XIV Simpósio Nacional de Sistemas Prediais

Gestão, Eficiência e Sustentabilidade

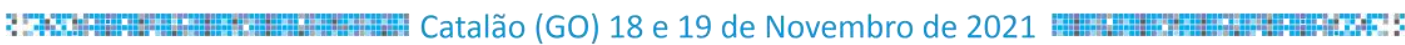

\title{
ANÁLISE DOS REGISTROS DE MANUTENÇÃO DE SISTEMAS PREDIAIS HIDROSSANITÁRIOS CONSIDERANDO O IMPACTO DA PANDEMIA DO SARS- COV-2 (COVID-19)
}

\section{Analysis of maintenance records of plumbing systems considering the impact of the SARS-CoV-2 (Covid-19) Pandemic}

\author{
MORAIS, Lucas Salomão Rael ${ }^{1}$; PAULA, Heber Martins²; REIS, Ricardo Prado Abreu ${ }^{\mathbf{3}}$
}

Recebido em 15 de julho de 2021, aprovado em 06 de setembro de 2021, publicado em 18 de novembro de 2021

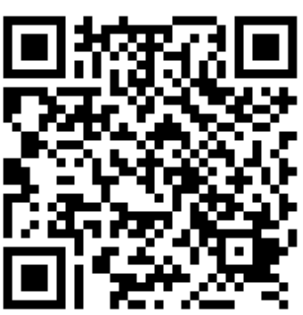

Palavras-chave:

Sistemas prediais hidrossanitários,

Patologias de construção,

Manutenção predial,

SARS-CoV-2 (covid-19).

Keywords:

Plumbing systems,

Building Pathologies,

Building maintenance,

SARS-CoV-2 (covid-19).
RESUMO: As edificações destinadas a instituições universitárias sempre se caracterizaram pelo uso intenso de suas instalações. Porém essa particularidade transformou-se completamente com o avanço da pandemia de SARS-CoV-2 (covid-19) durante o ano de 2020. Este artigo visa realizar uma análise comparativa dos registros de manutenção dos edifícios da Universidade Federal de Goiás, localizados na cidade de Goiânia-GO, durante o período de 2016 a 2020, a fim de verificar o impacto da pandemia nas ações de manutenção dos sistemas prediais hidrossanitários, considerando que nesse período as atividades presenciais foram mínimas dentro do órgão. Para tanto, as requisições de manutenção predial foram classificadas e categorizadas. Foi verificada queda no número de registros no ano de 2020, porém não houve diferença significativa de participação percentual das solicitações referentes aos sistemas prediais e suas instalações. Observou-se uma queda maior nas demandas relativas ao sistema de esgoto sanitário e menor naquelas relacionadas ao sistema de drenagem de águas pluviais. Equipamentos sujeitos a interações diretas dos usuários receberam menores registros de manifestações patológicas quando comparado a anos anteriores, bem como entupimentos em aparelhos sanitários foram menos relatados.

ABSTRACT: Buildings for university institutions have always been characterized by the intense use of their facilities. However, this particularity was completely transformed with the advance of the SARS-CoV-2 (covid-19) pandemic during the year 2020. This paper aims to carry out a comparative analysis of the maintenance records of the buildings of the Federal University of Goiás, located in the city of Goiânia, state of Goiás, Brazil, during the period from 2016 to 2020, to verify the impact of this pandemic on the maintenance of plumbing systems, considering that during this period, in-person activities were minimal within the agency. For this purpose, building maintenance requests were classified and categorized. There was a decrease in the number of registrations in the year 2020, but there was no significant difference in the percentage share of requests for building systems and their facilities. There was a greater drop in demands related to sewage drainage system and smaller in those related to stormwater drainage system. Equipment subject to direct user interactions received fewer records of pathological manifestations when compared to previous years, as well as clogging in sanitary fittings were less reported.

\footnotetext{
CONTATO DOS AUTORES:

${ }^{1}$ MORAIS, Lucas Salomão Rael: Mestrando em Engenharia Civil do Programa de Pós-graduação em Engenharia Civil da Universidade Federal Catalão, lucas.salomao@ufg.br

2 PAULA, Heber Martins: Eng. Civil, Doutor, Professor do Programa de Pós-graduação em Engenharia Civil da Universidade Federal Catalão, heberdepaula@ufcat.edu.br

${ }^{3}$ REIS, Ricardo Prado Abreu: Eng. Civil, Doutor, Professor da Escola de Engenharia Civil e Ambiental da Universidade Federal de Goiás, ricardo_reis@ufg.br
} 


\section{INTRODUÇÃO}

Os sistemas prediais representam a grande maioria das demandas de manutenção e conservação de uma edificação, tanto em instituições públicas quanto privadas. Nesse contexto, CRUZ (2013) e PRADO (2017) apontam que o Sistema Predial Hidrossanitário (SPHS) é o de maior participação em número de solicitações de assistência técnica no período de uso e operação, apresentando percentuais que vão de $19,3 \%$ até $49,62 \%$ em relação ao número total de solicitações de manutenção.

CONCEIÇÃO (2007) aponta que após a entrega da construção, o SPHS está entre os que mais sofrem solicitações distintas devido a interação com as necessidades dos usuários. Portanto, essas instalações tem tendência de serem os maiores elementos fontes de manutenção de um edifício, conforme verificado nos levantamentos de CRUZ (2013) e PRADO (2017).

As edificações destinadas a instituições universitárias se caracterizam por atenderem um grande número de usuários e pelo uso intenso de suas instalações. Porém, essa particularidade transformou-se completamente com o avanço da pandemia de SARS-CoV-2 (covid-19) durante o ano de 2020, quando as atividades presenciais nas universidades foram reduzidas de forma significativa em função das medidas restritivas de isolamento e de distanciamento social utilizadas como meios de conter a disseminação do vírus.

A partir dessas medidas, as aulas presenciais nas instituições foram suspensas e a presença de pessoas/usuários nos edifícios foi mínima, considerando as recomendações de trabalho "home office" e isolamento social. Neste cenário, pode-se considerar que as influências do usuário nos sistemas prediais foram praticamente nulas.

Considerando o contexto da ocorrência da pandemia de SARS-CoV-2 (covid-19), as medidas contenção e disseminação da doença e seus impactos nos sistemas prediais, este artigo tem como objetivo principal apresentar uma análise comparativa dos registros de manutenção predial dos edifícios da Universidade Federal de Goiás (UFG), localizados na cidade de Goiânia (GO), durante o período de 2016 a 2020, a fim de verificar o impacto da pandemia de SARSCoV-2 (covid-19) (ano 2020) nas requisições referentes ao sistema hidrossanitário, considerando a diminuição das atividades presenciais nesse período.

\section{MATERIAL E MÉTODOS}

\subsection{Caracterização do sistema de manutenção}

O estudo foi realizado nos edifícios da Universidade Federal de Goiás (UFG) localizados na cidade de Goiânia (GO), os quais realizou-se o levantamento da área construída e sua variação ao longo dos anos. A gestão da infraestrutura do órgão é realizada pela própria instituição, que recebe as demandas de manutenção através de softwares de gerenciamento. $O$ sistema Módulo de Ordem de Serviço Predial (MOSP) esteve vigente entre o ano de 2009 até meados de outubro de 2019. A partir desse período, foi implantado o Sistema Integrado de Patrimônio, Administração e Contratos (SIPAC) que está em vigência até os dias de hoje.

Para a execução dos serviços de manutenção, a equipe operacional é composta em sua grande maioria por colaboradores de empresas terceirizadas contratadas exclusivamente para a prestação de serviços de mão de obra. Os materiais necessários para execução dos reparos e serviços são provenientes da própria instituição, adquiridos por meio de contratações previstas na lei de licitação federal. 


\subsection{Avaliação dos dados}

Foram avaliados registros de ordens de serviço de manutenção predial referentes ao período de 2016 a 2020. Essa análise foi realizada através de relatórios emitidos pelo órgão dos programas MOSP e SIPAC, obtidos por meio de solicitação ao departamento de tecnologia e informação da instituição ou extração através de opções disponíveis no programa de registro de ordens de serviço vigente. A partir da análise da evolução da área construída da instituição e do número de requisições de manutenção predial recebidas anualmente, buscou-se relacionar esses dois dados a partir do parâmetro de número de requisições por $100 \mathrm{~m}^{2}$ de área construída (adaptado de MORAIS e LORDSLEEM (2018)).

Após a obtenção dos relatórios, iniciou-se a classificação das requisições de manutenção. Para tanto, foi utilizada inicialmente a classificação de categorias constantes nos relatórios para a separação das requisições referentes aos sistemas prediais. Para os sistemas elétricos, a categoria de tipo de serviço existente era nomeada de "elétrico", para os sistemas hidrossanitários, essa categoria era chamada de "hidráulico". Foram ainda utilizadas palavraschave e termos relacionados para a verificação de requisições preenchidas em categorias incorretas, como por exemplo "torneira", "água", "caixa", "esgoto", "chuva" e "telhado".

Posteriormente, as requisições receberam duas classificações:

- 1a Classificação de dados: categorização das requisições de todos os sistemas prediais, que já estavam separadas por categoria juntamente com aquelas existentes em categorias incorretas, identificadas pelas palavras-chave. O objetivo desse procedimento foi a identificação das requisições referentes aos sistemas prediais.

- 2a Classificação de dados: baseou-se na separação das requisições dos SPHS em função do tipo de sistema: água fria, esgoto sanitário, águas pluviais e ar condicionado (drenos). Nesta fase, foi necessário realizar a leitura de cada requisição para identificação do sistema correspondente.

Como critério de classificação e avaliação das requisições em relação ao sistema predial correspondente, foi considerado o tipo de fluido (água, esgoto ou água pluvial) que é conduzido pelo componente, peça sanitária ou louça.

\section{RESULTADOS E DISCUSSÃO}

Realizados os levantamentos das edificações existentes e a avaliação dos relatórios de manutenção, verificou-se crescimento constante de área construída da instituição acompanhado por registros de requisições de manutenção acima de treze mil para a maioria do período de uso regular das edificações, conforme apresentado no Quadro 1 . O número de requisições a cada $100 \mathrm{~m}^{2}$ registrou queda a partir do ano de 2018 até o ano de 2020.

O ano de 2019 apresentou queda no número de requisições quando comparado aos registros dos anos anteriores, que pode ser explicada pelo processo de transição entre dois sistemas eletrônicos de registro de requisições de manutenção predial ocorrido naquele ano. Um sistema de registro novo que demanda treinamento e familiaridade por parte do usuário pode ter afetado a frequência de cadastro de solicitações.

$\mathrm{O}$ ano de 2020 também foi bastante singular, pois a volta às aulas daquele ano letivo foi suspensa devido ao agravamento da pandemia de SARS-CoV-2 (covid-19) no país. Durante todo o período de 2020 a ocupação presencial na instituição foi irrisória. Nesse período, houve 
uma redução de $61,63 \%$ do número total de requisições, quando comparada à média de registros dos quatro anos anteriores.

Quadro 1 - Evolução anual de área construída acumulada e requisições de manutenção predial em números absolutos e por $100 \mathrm{~m}^{2}$ de área construída

\begin{tabular}{|c|c|c|c|}
\hline Ano & Área Construída $\mathbf{( m}^{\mathbf{2}} \mathbf{)}$ & Total de Requisições & $\begin{array}{c}\text { No de requisições a } \\
\text { cada } \mathbf{1 0 0} \mathbf{~ m}^{\mathbf{2}}\end{array}$ \\
\hline 2016 & $291.332,65$ & 13048 & 4,479 \\
\hline 2017 & $298.304,03$ & 13635 & 4,571 \\
\hline 2018 & $300.984,96$ & 13044 & 4,334 \\
\hline 2019 & $304.034,23$ & 11928 & 3,923 \\
\hline 2020 & $311.465,97$ & 4955 & 1,591 \\
\hline
\end{tabular}

Fonte: Autoria própria

Os Quadros 2, 3 e 4 trazem a variação dos registros em números absolutos, sendo possível comparar as requisições do ano de 2020 com a média de registros existentes nos quatro anos anteriores. No Quadro 2 observa-se que houve uma queda menor nas requisições referentes aos sistemas prediais que em outros tipos de requisições, contudo, é verificado o impacto no número de ocorrências durante o ano de 2020, influenciado pela pandemia. Dentre os sistemas prediais observados, o de telecomunicações apresentou a queda mais significativa. Conforme Quadro 3, os registros de manutenção em SPHS apresentaram uma redução menor que a do total de requisições e um aumento na participação percentual em relação aos outros sistemas. Avaliando somente os SPHS, observa-se que o sistema de drenagem de águas pluviais representou a menor queda do número absoluto de requisições $(15,67 \%)$ e um aumento de participação em relação aos anos anteriores, enquanto que o sistema de esgoto sanitário registrou a maior queda $(65,43 \%)$ e diminuição da participação percentual.

Quadro 2 - Variação dos registros de requisições de manutenção

\begin{tabular}{|l|c|c|c|}
\hline \multicolumn{1}{|c|}{ Tipo de requisição } & $\begin{array}{c}\text { Média de registros } \\
\text { entre 2016 e 2019 }\end{array}$ & $\begin{array}{c}\text { Registros no ano de } \\
\mathbf{2 0 2 0}\end{array}$ & $\begin{array}{c}\text { Diferença } \\
\text { percentual }\end{array}$ \\
\hline Total de requisições & 12913,75 & 4955 & $61,63 \%$ \\
\hline Total requisições dos sistemas prediais & 8327,25 & 3297 & $60,41 \%$ \\
\hline Outras requisições & 4586,50 & 1658 & $63,85 \%$ \\
\hline
\end{tabular}

Fonte: Autoria própria

Quadro 3 - Variação dos registros de requisições dos tipos de sistemas prediais

\begin{tabular}{|l|c|c|c|c|c|}
\hline \multicolumn{1}{|c|}{$\begin{array}{c}\text { Tipo de sistema } \\
\text { predial }\end{array}$} & $\begin{array}{c}\text { Média de } \\
\text { registros entre } \\
\text { 2016 e 2019 }\end{array}$ & $\begin{array}{c}\text { Participação } \\
\text { Percentual }\end{array}$ & $\begin{array}{c}\text { Registros no } \\
\text { ano de 2020 }\end{array}$ & $\begin{array}{c}\text { Participação } \\
\text { Percentual }\end{array}$ & $\begin{array}{c}\text { Redução das } \\
\text { solicitações } \\
\text { ano 2020 }\end{array}$ \\
\hline Elétrico & 2985,00 & $35,85 \%$ & 1320 & $40,04 \%$ & $55,78 \%$ \\
\hline Hidrossanitário & 3216,25 & $38,62 \%$ & 1378 & $41,80 \%$ & $57,16 \%$ \\
\hline Telecomunicações & 1989,75 & $23,89 \%$ & 553 & $16,77 \%$ & $72,21 \%$ \\
\hline Ar condicionado & 136,25 & $1,64 \%$ & 46 & $1,40 \%$ & $66,24 \%$ \\
\hline Total de Solicitações & 8327,25 & $100,00 \%$ & 3297 & $100,00 \%$ & $60,41 \%$ \\
\hline
\end{tabular}

Fonte: Autoria própria. 
Quadro 4 - Variação dos registros de requisições por tipo de SPHS

\begin{tabular}{|l|c|c|c|c|c|}
\hline \multicolumn{1}{|c|}{ Tipo de SPHS } & $\begin{array}{c}\text { Média de } \\
\text { registros entre } \\
\text { 2016 e 2019 }\end{array}$ & $\begin{array}{c}\text { Participação } \\
\text { Percentual }\end{array}$ & $\begin{array}{c}\text { Registros no } \\
\text { ano de 2020 }\end{array}$ & $\begin{array}{c}\text { Participação } \\
\text { Percentual }\end{array}$ & $\begin{array}{c}\text { Redução das } \\
\text { solicitações } \\
\text { ano 2020 }\end{array}$ \\
\hline Água fria & 1252,50 & $42,46 \%$ & 568 & $42,58 \%$ & $54,65 \%$ \\
\hline Esgoto sanitário & 1336,50 & $45,31 \%$ & 462 & $34,63 \%$ & $65,43 \%$ \\
\hline Águas pluviais & 360,50 & $12,22 \%$ & 304 & $22,79 \%$ & $15,67 \%$ \\
\hline Total de Solicitações & 2949,50 & $100,00 \%$ & 1334 & $100,00 \%$ & - \\
\hline
\end{tabular}

A Figura 1 aponta a participação percentual dos sistemas prediais nas requisições para cada ano avaliado. Através dos resultados, é possível verificar que mesmo o ano de 2020 registrando queda em números totais absolutos, o percentual das requisições referentes aos sistemas prediais se manteve estável quando comparado aos anos anteriores. Durante todo o período, os sistemas prediais constituem a maioria das demandas de manutenção predial.

Figura 1 - Participação dos sistemas prediais na manutenção predial por ano

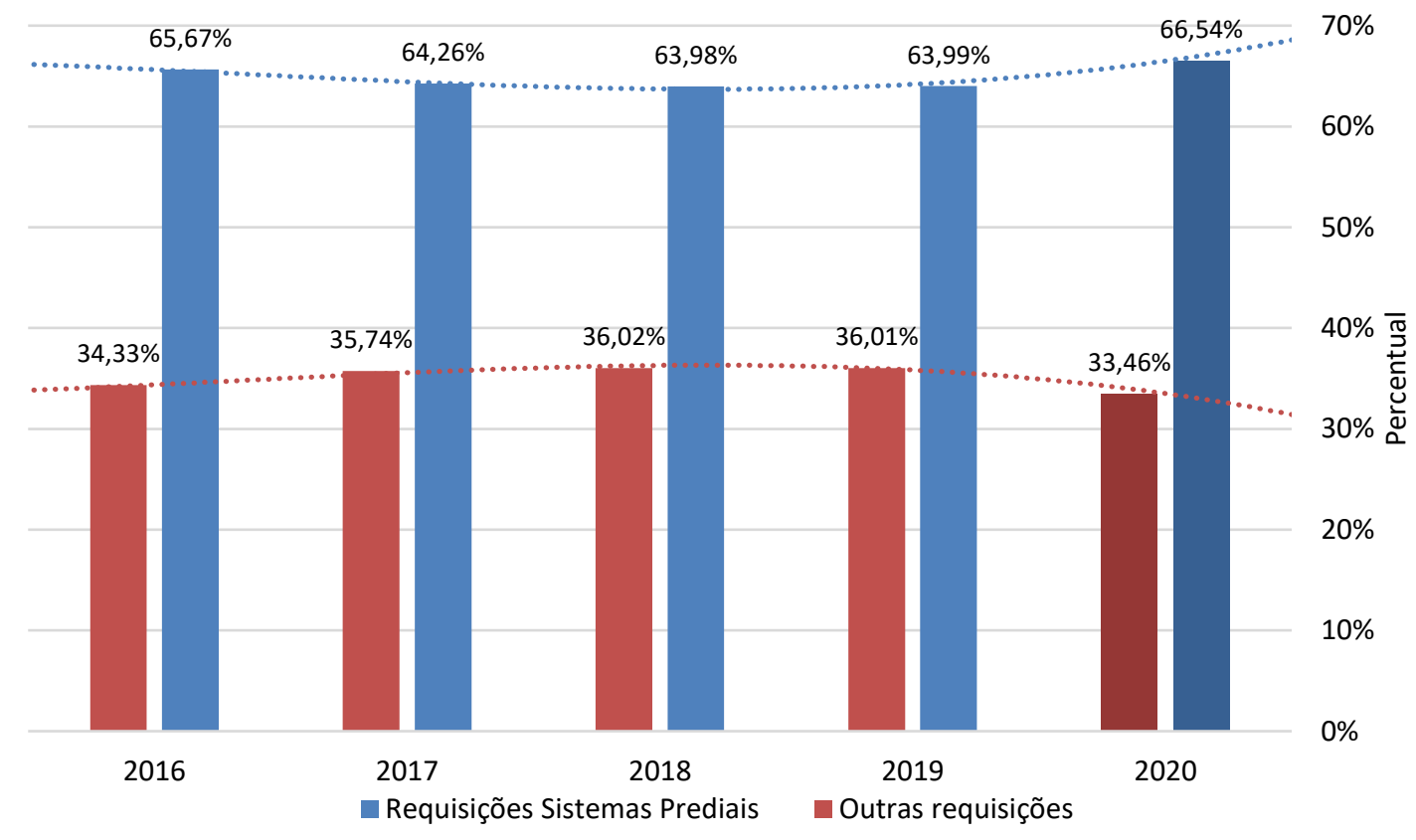

Fonte: Autoria própria.

A Figura 2 discrimina a representatividade de cada tipo de sistema predial por ano em relação ao total de solicitações. É possível observar que o ano de 2020 se caracterizou pelo aumento proporcional da participação dos registros de manutenção de SPHS e do elétrico, enquanto que houve redução considerável de requisições referentes ao sistema de telecomunicações. 
Figura 2 - Participação dos tipos sistemas prediais na manutenção predial por ano com relação ao total de registros de manutenção

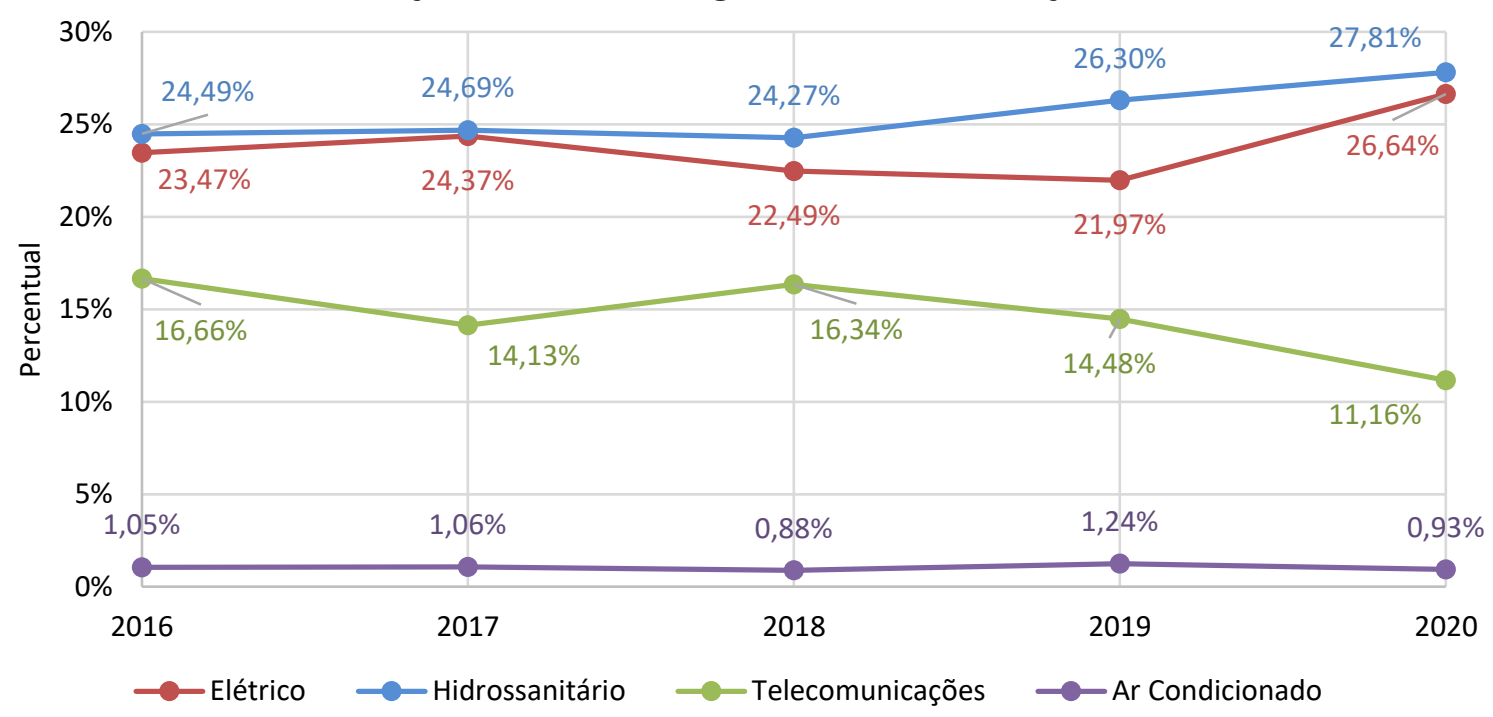

Fonte: Autoria própria.

A avaliação das requisições de manutenção pertencentes aos SPHS e a classificação, em função do tipo de sistema correspondente, estão apresentadas na Figura 3. Observa-se que, no ano de 2020, a participação do sistema de drenagem de águas pluviais nas requisições apresentou um aumento de mais de $10 \%$, o que se relaciona com a queda no percentual de solicitações relativas ao sistema de esgoto sanitário e outras requisições (não identificadas ou incorretas). Durante o período de 2020, o sistema de esgoto sanitário, que quase sempre representava a maioria das requisições, perdeu espaço para o sistema de água fria, que apresentou participação de 41,22\%.

Figura 3 - Participação de cada tipo de SPHS nos registros de manutenção predial por ano

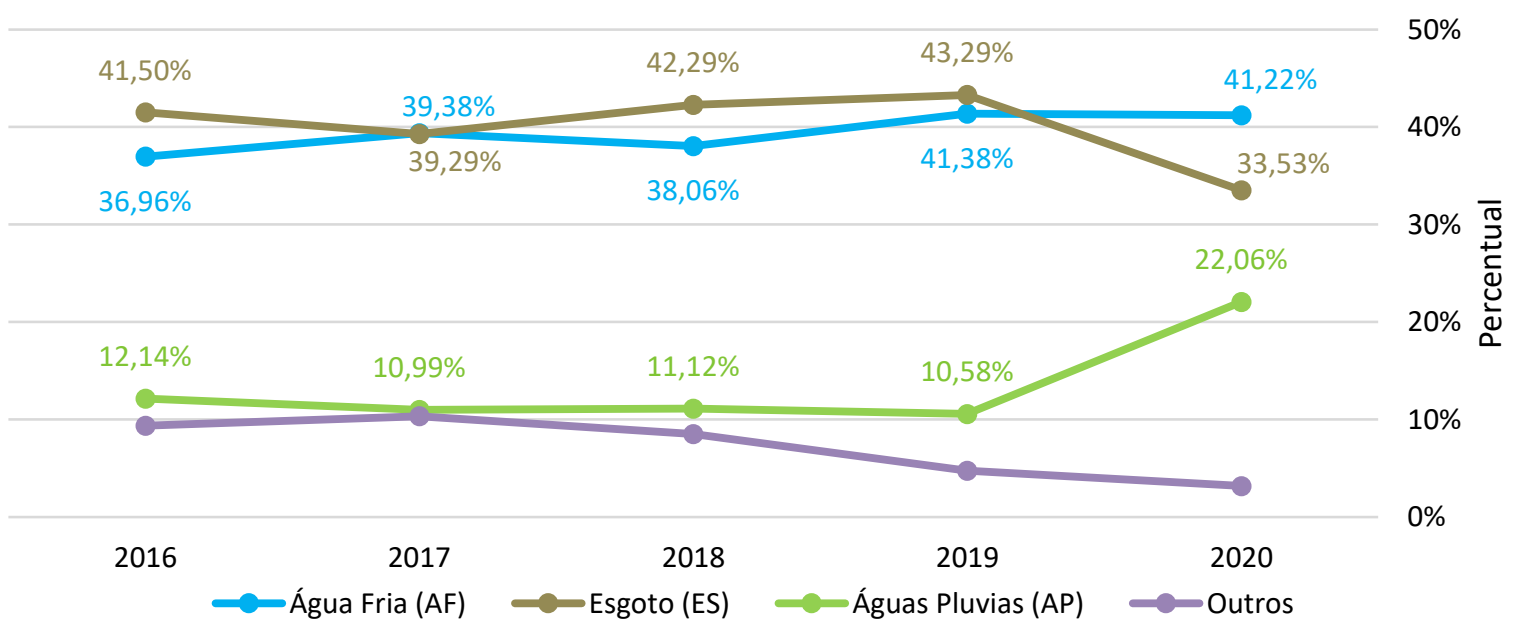

Fonte: Autoria própria.

As Figuras 4, 5 e 6 apresentam o percentual de requisições mensais em relação ao total daquele ano, a fim de avaliar a periodicidade das solicitações referentes aos SPHS. Observouse para os sistemas de água fria e esgoto sanitário que ao longo do ano de 2020 houve um maior número de requisições solicitadas durante os primeiros e últimos meses do ano (janeiro, fevereiro, março, novembro e dezembro), diferente dos anos anteriores, quando os 
meses de maio, junho, agosto e setembro registravam números elevados de solicitações e os meses de novembro e dezembro eram menos significativos. Isso pode ser explicado pelo fato de que, apesar de não existirem atividades intensas de usuários nessas instalações, a não execução de atividades regulares de manutenção preventiva ocasionou o acúmulo de ocorrências para o período de fim de ano, quando usualmente os gestores das unidades fazem solicitações de vistorias de manutenção. Deve-se ressaltar que, demandas registradas no início do ano de 2020 podem ser reflexo do uso e desgaste das instalações e equipamentos durante no ano anterior.

A periodicidade das requisições referentes ao sistema de drenagem de águas pluviais (Figura 6) depende geralmente do regime de chuvas de cada ano, porém observou-se também um maior número de solicitações no início e no fim do ano de 2020.

\section{Figura 4 - Periodicidade das requisições referentes ao sistema de água fria}

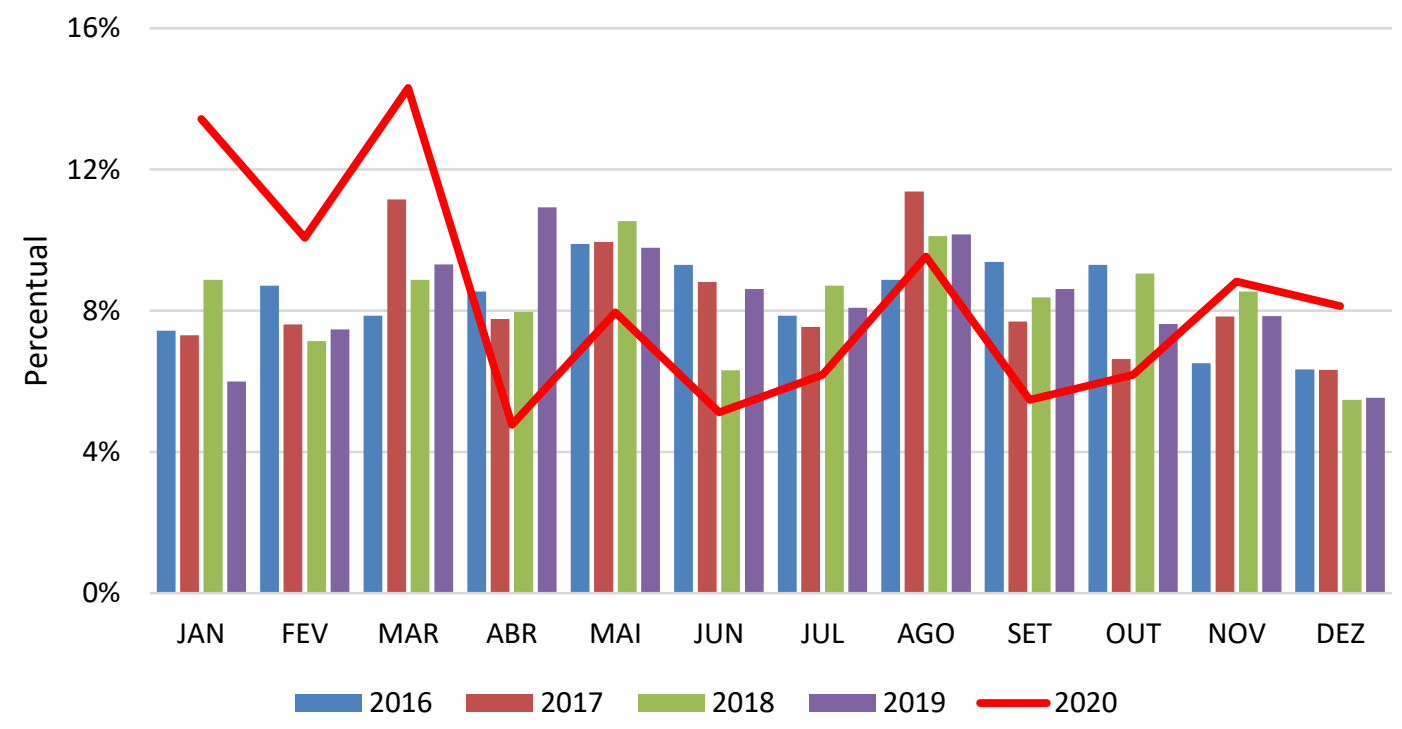

Fonte: Autoria própria.

Figura 5 - Periodicidade das requisições referentes ao sistema de esgoto sanitário

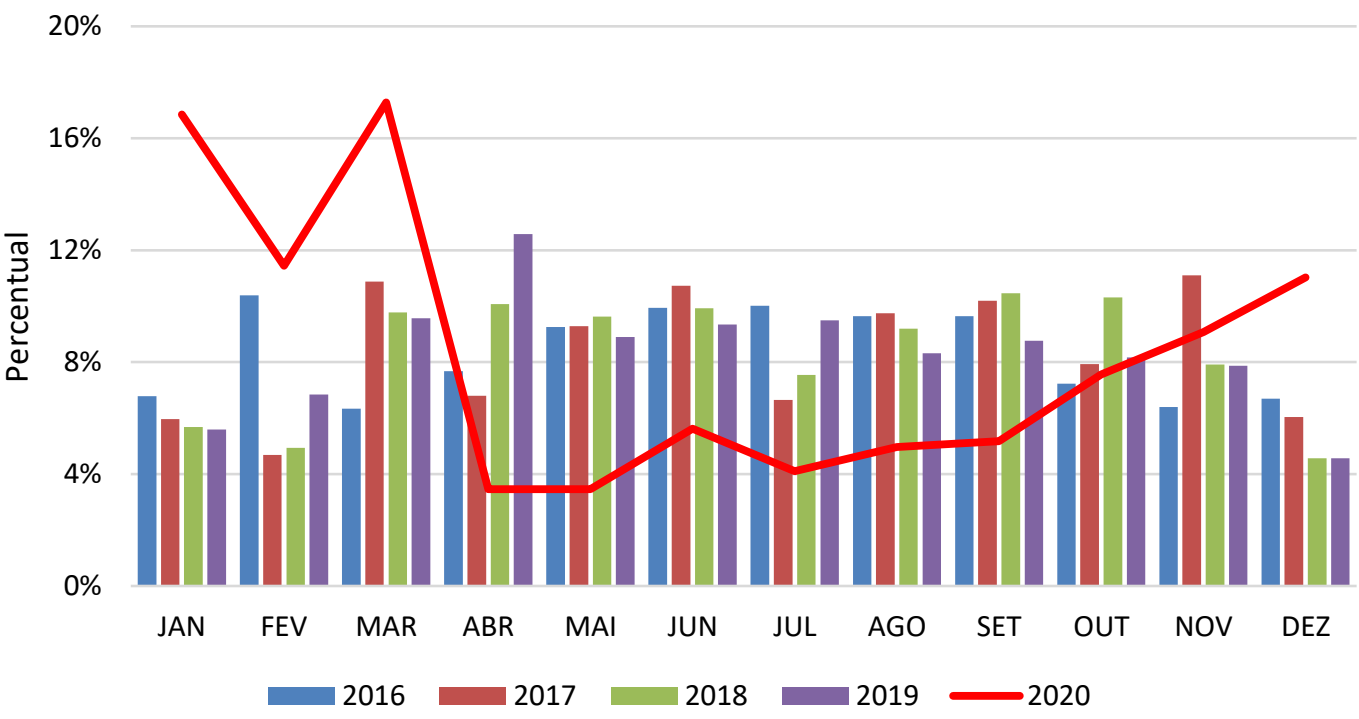

Fonte: Autoria própria. 
Figura 6 - Periodicidade das requisições referentes ao sistema de drenagem de águas pluviais

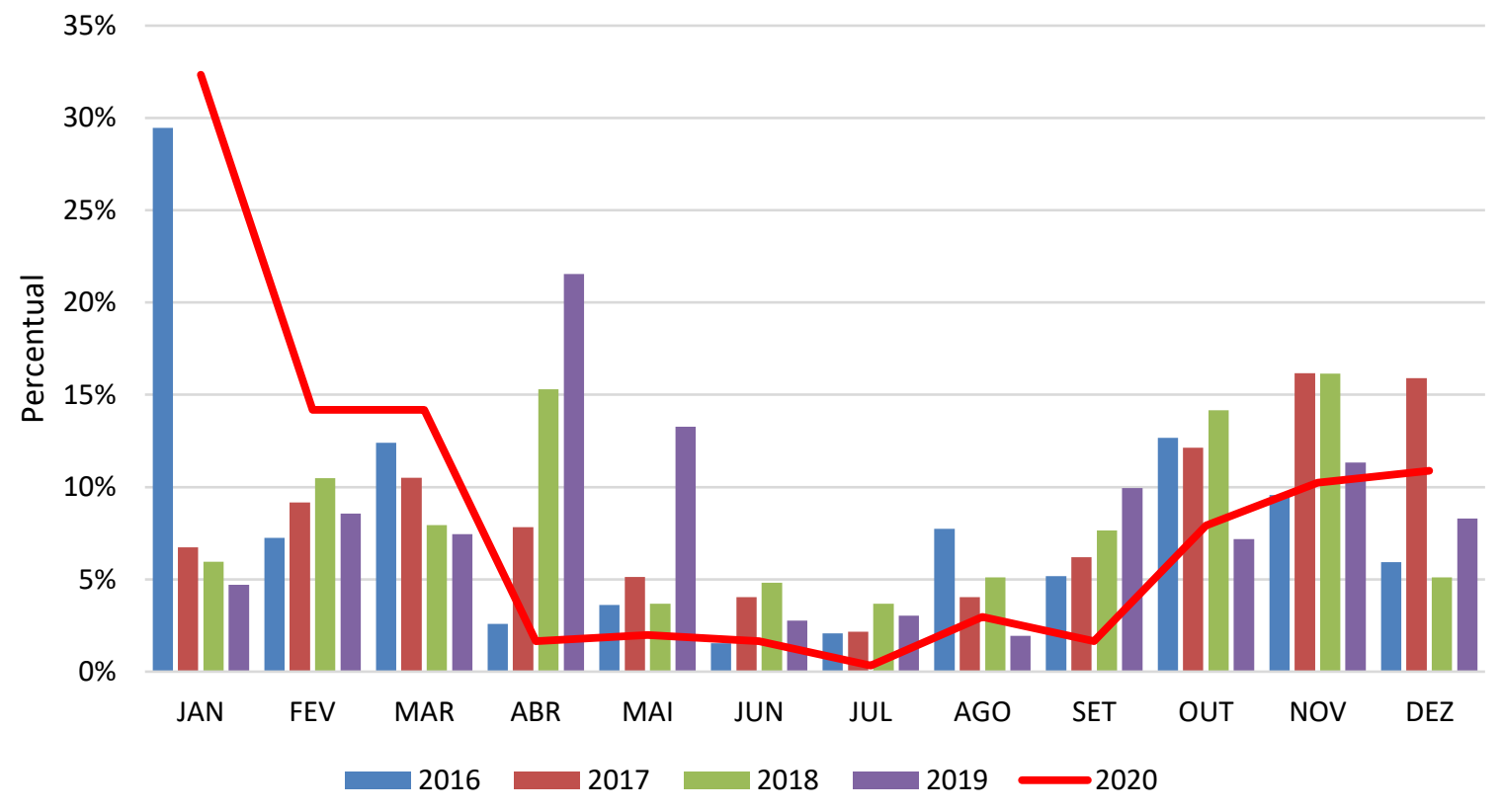

Fonte: Autoria própria.

Os Quadros 7, 8 e 9 apresentam a participação percentual e a variação do número de registros das manifestações patológicas mais comuns reportadas nas demandas de manutenção dos SPHS verificadas durante o ano de 2020 e a média entre os anos de 2016 e 2019. De forma geral, todas as falhas registradas tiveram queda no número de solicitações durante o período, mas observa-se redução menor nos registros do sistema de drenagem de águas pluviais.

Para o sistema de água fria, destaca-se redução de demandas em vazamentos e defeitos em válvulas de descarga, torneiras e chuveiros, equipamentos que mais recebem solicitações dos usuários em condições normais de uso. No sistema de esgoto sanitário, as ocorrências referentes a entupimentos foram as que mais diminuíram, tanto em bacias sanitárias, ralos, mictórios, caixas de passagem e de gordura.

Em relação a participação percentual, não foram verificadas diferenças significativas entre os anos anteriores e 2020, com exceção para ao sistema de esgoto sanitário que apresentou redistribuição entre as demandas relacionadas as bacias sanitárias (redução), ralos (redução), pias e sifões (aumento).

Um fato interessante a se notar para o sistema de drenagem de águas pluviais é que os registros de manutenção com maiores reduções foram os referentes a vazamentos e entupimentos em ralos, grelhas e caixas de areia, ou seja, serviços de fácil intervenção e execução, o que não acontece nas solicitações relativas a vazamentos em telhados, calhas e goteiras, que são serviços de maior complexidade de solução e maiores expensas financeiras. Portanto, é possível inferir que demandas de períodos chuvosos de anos anteriores sejam reincidentes no ano de 2020. 
Quadro 7 - Variação das manifestações relatadas referentes ao sistema de água fria

\begin{tabular}{|l|c|c|c|c|c|}
\hline \multicolumn{1}{|c|}{ Descrição } & $\begin{array}{c}\text { Média de registros } \\
\text { entre 2016 e 2019 }\end{array}$ & $\begin{array}{c}\text { Participação } \\
\text { Percentual }\end{array}$ & $\begin{array}{c}\text { Registros no } \\
\text { ano de 2020 }\end{array}$ & $\begin{array}{c}\text { Participação } \\
\text { Percentual }\end{array}$ & $\begin{array}{c}\text { Diferença } \\
\text { percentual }\end{array}$ \\
\hline $\begin{array}{l}\text { Vazamentos e defeitos em } \\
\text { torneiras }\end{array}$ & 449,50 & $38,12 \%$ & 186 & $36,76 \%$ & $58,62 \%$ \\
\hline $\begin{array}{l}\text { Vazamentos e defeitos em } \\
\text { válvulas de descarga }\end{array}$ & 180,75 & $15,33 \%$ & 66 & $13,04 \%$ & $63,49 \%$ \\
\hline $\begin{array}{l}\text { Vazamentos e defeitos em } \\
\text { registros }\end{array}$ & 94,50 & $8,01 \%$ & 45 & $8,89 \%$ & $52,38 \%$ \\
\hline $\begin{array}{l}\text { Vazamentos em tubulações } \\
\text { Vazamentos em tubulações de } \\
\text { chuveiros }\end{array}$ & 242,00 & $20,52 \%$ & 119 & $23,52 \%$ & $50,83 \%$ \\
\hline $\begin{array}{l}\text { Vazamentos em tubulações de } \\
\text { bomba }\end{array}$ & 26,75 & $2,27 \%$ & 9 & $3,75 \%$ & $58,92 \%$ \\
\hline $\begin{array}{l}\text { Vazamentos e falhas em } \\
\text { reservatórios }\end{array}$ & 129,50 & $10,98 \%$ & 57 & $11,26 \%$ & $55,98 \%$ \\
\hline $\begin{array}{l}\text { Vazamentos e defeitos em } \\
\text { engates }\end{array}$ & 10,00 & $0,85 \%$ & 5 & $0,99 \%$ & $50,00 \%$ \\
\hline Total de Solicitações & 1179,25 & $100,00 \%$ & 506 & $100,00 \%$ & $66,36 \%$ \\
\hline
\end{tabular}

Fonte: Autoria própria.

\section{Quadro 8 - Variação das manifestações relatadas referentes ao sistema de esgoto sanitário}

\begin{tabular}{|l|c|c|c|c|c|}
\hline \multicolumn{1}{|c|}{ Descrição } & $\begin{array}{c}\text { Média de registros } \\
\text { entre 2016 e 2019 }\end{array}$ & $\begin{array}{c}\text { Participação } \\
\text { Percentual }\end{array}$ & $\begin{array}{c}\text { Registros no } \\
\text { ano de 2020 }\end{array}$ & $\begin{array}{c}\text { Participação } \\
\text { Percentual }\end{array}$ & $\begin{array}{c}\text { Diferença } \\
\text { percentual }\end{array}$ \\
\hline $\begin{array}{l}\text { Vazamentos e defeitos em pias e } \\
\text { sifões }\end{array}$ & 461 & $33,32 \%$ & 224 & $48,38 \%$ & $51,41 \%$ \\
\hline $\begin{array}{l}\text { Vazamentos e entupimentos em } \\
\text { bacias sanitárias }\end{array}$ & 444,75 & $32,14 \%$ & 106 & $22,89 \%$ & $76,17 \%$ \\
\hline $\begin{array}{l}\text { Entupimentos em ralos } \\
\text { Vazamentos e entupimentos em } \\
\text { mictórios }\end{array}$ & 143,75 & $10,39 \%$ & 8 & $1,73 \%$ & $94,43 \%$ \\
\hline $\begin{array}{l}\text { Vazamentos e entupimentos em } \\
\text { caixas de gordura e caixas de } \\
\text { passagem }\end{array}$ & 215,25 & $15,56 \%$ & 75 & $16,20 \%$ & $65,16 \%$ \\
\hline $\begin{array}{l}\text { Vazamentos e entupimentos em } \\
\text { tubulações }\end{array}$ & 92,5 & $6,68 \%$ & 34 & $7,34 \%$ & $63,24 \%$ \\
\hline $\begin{array}{l}\text { Total de Solicitações } \\
\text { Pas, }\end{array}$ & 1383,75 & $100,00 \%$ & 463 & $100,00 \%$ & - \\
\hline
\end{tabular}

Fonte: Autoria própria 
Quadro 9 - Variação das manifestações relatadas referentes ao sistema de drenagem de águas pluviais

\begin{tabular}{|l|c|c|c|c|c|}
\hline \multicolumn{1}{|c|}{ Descrição } & $\begin{array}{c}\text { Média de registros } \\
\text { entre 2016 e 2019 }\end{array}$ & $\begin{array}{c}\text { Participação } \\
\text { Percentual }\end{array}$ & $\begin{array}{c}\text { Registros no } \\
\text { ano de 2020 }\end{array}$ & $\begin{array}{c}\text { Participação } \\
\text { Percentual }\end{array}$ & $\begin{array}{c}\text { Diferença } \\
\text { percentual }\end{array}$ \\
\hline $\begin{array}{l}\text { Vazamentos e entupimentos } \\
\text { em calhas }\end{array}$ & 68,75 & $18,19 \%$ & 58 & $20,21 \%$ & $15,64 \%$ \\
\hline Vazamentos em telhados & 212,5 & $56,22 \%$ & 167 & $58,19 \%$ & $21,41 \%$ \\
\hline $\begin{array}{l}\text { Vazamentos e entupimentos } \\
\text { em ralos e grelhas }\end{array}$ & 15,75 & $4,17 \%$ & 6 & $2,09 \%$ & $61,90 \%$ \\
\hline $\begin{array}{l}\text { Vazamentos e entupimentos } \\
\text { em rufos }\end{array}$ & 5 & $1,32 \%$ & 3 & $1,05 \%$ & $40,00 \%$ \\
\hline Ocorrência de goteiras & 62,75 & $16,60 \%$ & 51 & $17,77 \%$ & $18,73 \%$ \\
\hline $\begin{array}{l}\text { Vazamentos e entupimentos } \\
\text { em caixas de areia }\end{array}$ & 13,25 & $3,51 \%$ & 2 & $0,70 \%$ & $84,91 \%$ \\
\hline Total de Solicitações & 378 & $100,00 \%$ & 287 & $100,00 \%$ & - \\
\hline
\end{tabular}

Fonte: Autoria própria.

\section{CONSIDERAÇÕES FINAIS}

A partir da avaliação dos dados, verificou-se que apesar do ano de 2020 registrar queda significativa em números absolutos de todos os tipos de demandas de manutenção, a proporção de requisições referentes aos sistemas prediais e suas instalações e a participação percentual de ocorrência de manifestações patológicas se mantiveram similares aos anos anteriores. Nos SPHS é observada redução em números absolutos maior no sistema de esgoto sanitário e menor no sistema de drenagem de águas pluviais, devido ao fato de haver um número menor de usuários utilizando o SPHS, o que reflete menores demandas relacionadas a entupimentos de aparelhos sanitários, enquanto que as ocorrências relacionadas aos sistemas de cobertura tem relação menor com a presença de usuários na edificação.

A maioria das requisições foram registradas nos primeiros e últimos meses do ano, o que indica que grande parte dessas demandas eram referentes a problemas do ano anterior e devido a vistorias de manutenção solicitadas por gestores das unidades acadêmicas que ocorrem a cada fim de ano.

Devido a diminuição do usuário nas edificações, as manifestações patológicas que mais registraram queda de solicitações foram referentes a torneiras, válvulas de descarga e chuveiros, equipamentos que recebem interações diretas dos usuários em períodos normais de uso. A diminuição de demandas relatando entupimentos também refletem a menor presença do público junto a essas instalações.

A avaliação do histórico da instituição indica que o SPHS é o sistema que mais apresenta ordens de serviço durante todo o período avaliado, sendo as demandas referentes ao sistema de esgoto sanitário a maioria dentre todos os registros avaliados. 


\section{REFERÊNCIAS}

ASSOCIAÇÃO BRASILEIRA DE NORMAS TÉCNICAS. NBR 5674:2012. Manutenção de Edificações. Procedimento. Rio de Janeiro: ABNT, 2012. 6p.

NBR 5626/2020. Sistemas prediais de água fria e água quente - Projeto, execução, operação e manutenção. Rio de Janeiro: ABNT, 1994. 56p.

CONCEIÇÃO, A. P. Estudo da incidência de falhas visando a melhoria da qualidade dos sistemas prediais hidráulicos e sanitários. 2007. 143f. Dissertação (Mestrado em Construção Civil) - Programa de Pós-Graduação em Construção Civil, Universidade Federal de São Carlos, São Carlos, 2007.

CRUZ, D. C. Análise de solicitações de assistência técnica em empreendimentos residenciais como ferramenta de gestão. 2013. 167 p. Dissertação (Mestrado em Estruturas e Construção Civil) Universidade Federal de Goiás, Goiânia, GO.

MORAIS, G. A. T.; LORDSLEEM, A. C. J. A Building maintenance management activities in a public institution. Engineering, Construction and Architectural Management, v. 26, ed.1, 2019. p85-103.

PRADO, G. B. Aplicação do método G.U.T. para priorização de intervenções em manifestações patológicas de sistemas prediais em edifícios universitários. 2017. 92 p. Dissertação (Mestrado em Estruturas e Construção Civil) - Universidade Federal de São Carlos, São Carlos, SP. 